\title{
IMPACT ASSESSMENT OF SOIL CONTAMINATED WITH POLLUTANTS ON CUCUMBER GROWTH
}

\author{
Augustina Pruteanu \\ National Institute of Research-Development for Machines and Installations Designed to Agriculture \\ and Food Industry, Romania \\ pruteanu_augustina@yahoo.com
}

\begin{abstract}
The purpose of this paper is to present the results of the research focused on samples of uncontaminated and contaminated soil in controlled environment (in pots) with different polluting substances $(\mathrm{Cu}, \mathrm{Pb}, \mathrm{Zn})$ and mixtures thereof, as well as the translocation of pollutants into cucumbers grown on these soils. The concentrations of the solutions of lead acetate, copper sulphate and zinc sulphate, with which the soil was contaminated were $1.5 \%, 3.0 \%, 4.5 \%, 6.0 \%$. The control sample consisted of uncontaminated fertile soil. A progressive increase of the metal content in the soil was observed for the four concentrations compared to the control sample $\left(17.6 \mathrm{mg} \cdot \mathrm{kg}^{-1} \mathrm{Cu} ; 6.8 \mathrm{mg} \cdot \mathrm{kg}^{-1} \mathrm{~Pb} ; 39.8 \mathrm{mg} \cdot \mathrm{kg}^{-1} \mathrm{Zn}\right)$. Also, the final metal content in plants was progressive compared to plants grown in uncontaminated soil $\left(5.2 \mathrm{mg} \cdot \mathrm{kg}^{-1} \mathrm{Cu} ; 2.7 \mathrm{mg} \cdot \mathrm{kg}^{-1} \mathrm{~Pb} ; 34.1 \mathrm{mg} \cdot \mathrm{kg}^{-1}\right.$ $\mathrm{Zn})$. The translocation coefficient recorded high values in uncontaminated soil $(0.257 \mathrm{Cu} ; 0.404 \mathrm{~Pb} ; 0.857 \mathrm{Zn})$ and low values in contaminated soil with a concentration of $6.0 \%(0.015 \mathrm{Cu}, 0.041 \mathrm{~Pb}, 0.101 \mathrm{Zn})$. Therefore, based on the experimental results obtained in the laboratory, the impact of soil and plant contamination was evaluated by developing statistical models under real conditions regarding the accumulation and transfer of pollutants from the soil into cucumber fruits. As many consumers buy fruits and vegetables contaminated with different pollutants that are harmful to their health and also to the environment, the results of the paper form an important basis for further research in this area.
\end{abstract}

Keywords: soil, pollutants, cucumbers.

\section{Introduction}

Worldwide, environmental pollution is increasing rapidly due to human activities, industrial production, mining, agriculture and transport, which release a large amount of heavy metals at the biosphere level. The main sources of metal pollution are burning of fossil fuels, melting of metals, municipal waste, fertilizers, pesticides and sewage $[1 ; 2]$.

Heavy metal pollution not only affects crop production and quality, but also influences the quality of the atmosphere, soil and water and threatens the health and life of animals and human beings through the food chain [1]. Heavy metal accumulation occurs only when plant crops are grown in a heavy metal contaminated environment; as a result, heavy metals enter the food chain. When heavy metal contaminated vegetables are consumed by human beings, they cause various serious health disorders. These heavy metals affect plants and human beings, also the soil nutrient status, soil health, water sources and also other living aquatic organisms [2].

Currently, food safety is a major concern. The growing demand for food safety has led to the acceleration of research into the risks associated with the consumption of heavy metal contaminated foods. The rate at which heavy metals accumulate in the soil depends on the physico-chemical properties of the soil and the efficiency of growing crops to remove metals from the soil. Heavy metals accumulated in cultivated soils can be transferred to humans through different routes of exposure that cause adverse effects on human health. The level of health risks presented by wastewater, soils and air contaminated with heavy metals was determined using different indices, including transfer factor (TF), daily intake of metals (DIM) and health risk index (HRI) or hazard quotient (HQ) [1].

The application of a large amount of heavy metals in soils was tested and it was shown that this affects the plant by the appearance of chlorosis, damage to the root tips, reduction of water in the plant and the absorption of nutrients, as well as affecting the enzymes. Vegetables, especially leafy ones, accumulate larger amounts of heavy metals, because they absorb these metals in their leaves [1].

Plants grown in soils polluted with $\mathrm{Zn}$ and $\mathrm{Cu}$ retain abundant portions of metals in the roots. Copper $(\mathrm{Cu})$ is known to be important and poisonous to many biological systems. Lead and cadmium have no favourable effects recognized in plants, their effects being only lethal [1].

In the world, there are many studies regarding the accumulation of metals from the soil in vegetables (cucumbers). In Iran, the authors of paper [3] investigated the levels of four heavy metals $(\mathrm{Zn}, \mathrm{Cd}, \mathrm{Pb}$ and $\mathrm{Cu})$ in cucumber and tomato samples from Golestan province. The results showed 
that the concentrations of $\mathrm{Cd}$ and $\mathrm{Pb}$ in cucumbers are estimated to be 2.4 to 14.4 times higher, while $\mathrm{Zn}$ and $\mathrm{Cu}$ levels were lower than the maximum allowable limit for vegetables. Two other studies conducted, one in China [4] and the other one in Palestine [5], showed that the most part of heavy metal content in vegetables (and cucumbers) did not exceed the national standard level, except for the $\mathrm{Pb}$ content that was higher.

Two other experiments were conducted in regions of Nigeria, one [6] conducted in 2014-2015 on the effect of organic waste, (fertilizers and manure) applied on soils contaminated with heavy metals and the growth characteristics of cucumbers on these soils, and another one [7] on the determination of concentrations of toxic heavy metals (lead, cadmium and copper) in some fruits and vegetables commonly grown and consumed.

The results obtained in the first experiment [6] showed that both fertilizer and manure were good organic sources, at the rates used, because they did not increase the properties of the heavy metals in the soil beyond the limits admitted by the WHO and they significantly improved the physico-chemical properties of the soil and the yield of cucumber growth. The results of the second experiment [7] indicated that the copper concentration was negligible in all cultures, and the highest concentrations were observed in lead. Finally, this study indicated that leafy vegetables, such as spinach, are more prone to absorb metals than fruit crops, such as cucumbers. The reason may be the result of different botanical structures of plants.

In Romania, there are studies [8;9] regarding vegetables contaminated with heavy metals, especially those cultivated in the mining areas of the country. The maximum allowed values were exceeded for $\mathrm{Mn}, \mathrm{Zn}, \mathrm{Cu}, \mathrm{Cd}$ and $\mathrm{Pb}$ for parsley roots and leaves, roots of carrot, cabbage, salad and cucumbers. The systematic consumption of vegetables and fruits polluted with heavy metals by the inhabitants of the polluted areas leads to the change of health and the emergence of chronic diseases with unpredictable end.

The present paper presents experimental results obtained in a controlled environment regarding the assessment of the impact of soil contamination with heavy metals and their translocation into cucumber fruits.

\section{Materials and methods}

Cucumber seedlings were planted in a controlled environment, in the greenhouse, in pots, in soil contaminated with four concentrations: $1.5 \%, 3.0 \%, 4.5 \%, 6.0 \%$ of each heavy metal: copper, lead, zinc and with mixtures of all these three metals and four concentrations. The heavy metal loading was done only through the initial loading without further supplementation until harvesting.

The solutions with concentrations of 1.5, 3.0, 4.5 and $6.0 \%$ were prepared individually using as reagent copper sulphate, lead acetate and $\mathrm{Zn}$ sulphate, the solvent used in the preparation of the solutions being distilled water. For the mixing of $\mathrm{Cu}, \mathrm{Pb}, \mathrm{Zn}$ solutions for each of the concentrations of $1.5,3.0,4.5$ and $6.0 \%$ individually prepared, equal parts were taken from each solution element respective concentration and were mixed until homogenization resulting the mixture.

The pots in which the cucumber seedlings were planted were filled with fertile soil, which was mixed and homogenized in turn with each of the four solutions of different concentrations. For each pot the soil added contained $250 \mathrm{ml}$ solution of $\mathrm{Cu}, \mathrm{Pb}, \mathrm{Zn}$ per $1 \mathrm{~kg}$ of soil.

Reported to the soil contaminated with the four solutions of different concentrations, in parallel, as reference samples, seedlings were planted in pots with uncontaminated fertile soil. The initial heavy metal content in the control plant is for the plant grown in intentionally uncontaminated soil, with the natural content of heavy metal.

The physico-chemical properties of the uncontaminated soil (considered as the control sample) were: $\mathrm{pH}$ 5.0-7.0; total nitrogen $1.9 \%$; total phosphorus $0.5 \%$; total potassium $0.9 \%$; electrical conductivity 1.2; particle elements over $20 \mathrm{~mm}$ maximum $5 \%$, humidity $14.7 \%$.

The methods of analysis were chosen according to the purpose pursued, namely: to evaluate the accumulation level of heavy metals at the soil - plants level. The content of heavy metals $\mathrm{Cu}, \mathrm{Pb}, \mathrm{Zn}$ from the ash of the samples prepared according to the type of material analysed (soil, plants) was determined using the atomic absorption spectrophotometer [10-12]. The methods and techniques chosen are in accordance with the recommendations elaborated by the Institute of Pedological and 
Agrochemical Research in Bucharest and the Romanian Standards regarding the elaboration of the pedological and agrochemical studies [13; 14].

The translocation coefficient $C_{t}$ studied in this paper reflects the ability of the plant to take over the heavy metal from the soil $C_{f p}$, depending on the concentration of heavy metal in the soil $C_{i s}$ [15].

The definition formula is:

$$
C_{t}=\frac{C_{f p}}{C_{i s}} .
$$

The experimental data were utilized in primary statistical models by ordinary polynomial interpolations [15; 16], using the Matchad program [17].

\section{Results and discussion}

The variations of the content of metals applied separately and in mixture to the soil, and their remainder in the plant, depending on the concentration of the contamination solution, and the translocation coefficients are shown in Tables 1 and 2.

Variations in the content of metals applied separately to the soil

Table 1 and their remainder in the plant and the translocation coefficient

\begin{tabular}{|c|c|c|c|c|c|c|c|c|c|}
\hline \multirow{2}{*}{$\begin{array}{c}\text { Concentration } \\
\text { of the } \\
\text { contamination } \\
\text { solution, } \%\end{array}$} & \multicolumn{3}{|c|}{$\begin{array}{l}\text { Initial content of metals } \\
\text { in the soil, } C_{i s}, \mathrm{mg}^{\cdot \mathrm{kg}^{-1}}\end{array}$} & \multicolumn{3}{|c|}{$\begin{array}{l}\text { Final content of metals } \\
\text { in the plant, } C_{f p}, \mathrm{mg} \cdot \mathrm{kg}^{-1}\end{array}$} & \multicolumn{3}{|c|}{$\begin{array}{l}\text { Translocation } \\
\text { coefficient, } C_{t}\end{array}$} \\
\hline & $\mathrm{Cu}$ & $\mathbf{P b}$ & $\mathbf{Z n}$ & $\mathbf{C u}$ & $\mathbf{P b}$ & $\mathbf{Z n}$ & $\mathrm{Cu}$ & $\mathbf{P b}$ & $\mathbf{Z n}$ \\
\hline 0 & 17.6 & 6.8 & 39.8 & 5.2 & 2.7 & 34.1 & 0.297 & 0.404 & 0.857 \\
\hline 1.5 & 58.9 & 48.7 & 202.7 & 6.0 & 12.8 & 45.0 & 0.102 & 0.263 & 0.222 \\
\hline 3.0 & 267.2 & 84.7 & 534.8 & 8.5 & 12.0 & 65.3 & 0.032 & 0.142 & 0.122 \\
\hline 4.5 & 525.1 & 117.7 & 921.7 & 8.3 & 9.5 & 84.5 & 0.016 & 0.081 & 0.092 \\
\hline 6.0 & 680.8 & 285.2 & 1052.3 & 10.0 & 11.8 & 106.3 & 0.015 & 0.041 & 0.101 \\
\hline
\end{tabular}

Variations in the content of metals applied in mixture to the soil and their remainder in the plant and the translocation coefficient

\begin{tabular}{|c|c|c|c|c|c|c|c|c|c|}
\hline \multirow{2}{*}{$\begin{array}{c}\text { Concentration } \\
\text { of the } \\
\text { contamination } \\
\text { solution, } \% \\
\end{array}$} & \multicolumn{3}{|c|}{$\begin{array}{l}\text { Initial content of metals } \\
\text { in the soil, } C_{i s}, \mathrm{mg} \mathrm{kg}^{-1}\end{array}$} & \multicolumn{3}{|c|}{$\begin{array}{l}\text { Final content of metals } \\
\text { in the plant, } C_{f p}, \mathrm{mg} \mathrm{kg}^{-1}\end{array}$} & \multicolumn{3}{|c|}{$\begin{array}{l}\text { Translocation } \\
\text { coefficient, } C_{t}\end{array}$} \\
\hline & $\mathbf{C u}$ & $\mathbf{P b}$ & Zn & $\mathrm{Cu}$ & $\mathbf{P b}$ & $\mathbf{Z n}$ & $\mathbf{C u}$ & $\mathbf{P b}$ & $\mathbf{Z n}$ \\
\hline 1.5 & 33.2 & 11.9 & 129.9 & 9.0 & 3.0 & 45.0 & 0.090 & 0.756 & 0.266 \\
\hline 3.0 & 72.4 & 54.1 & 253.5 & 12.0 & 4.0 & 54.5 & 0.055 & 0.222 & 0.215 \\
\hline 4.5 & 265.1 & 117.3 & 378.4 & 13.5 & 5.3 & 54.8 & 0.020 & 0.115 & 0.145 \\
\hline 6.0 & 378.2 & 152.8 & 454.3 & 9.5 & 7.8 & 54.2 & 0.020 & 0.062 & 0.119 \\
\hline
\end{tabular}

The data presented in tables 1 and 2, on the remanence and translocation of the metals from the soil to the plant, were used within some primary statistical models by ordinary polynomial interpolations, of first, second, third and fourth degrees, of the heavy metal content in the plant at harvest.

The general form of the interpolation polynomial (first-fourth degrees) is:

$$
C_{p}\left(C_{i s}\right)=c_{0}+c_{1} C_{i s}+c_{2} C_{i s}^{2}+c_{3} C_{i s}^{3}+c_{4} C_{i s}^{4} .
$$

The interpolation formulas can be used to forecast the heavy metal content accumulated in the plant and the translocation coefficient achieved at the end of the cucumber vegetation period. However, the forecast will be made only within the limits of the initial concentration range in the soil given by the minimum and maximum values of the concentrations used in experiments. 
Interpolation equations corresponding to the metal content in cucumbers (fruit)

\begin{tabular}{|c|c|c|c|c|c|c|c|}
\hline \multirow{2}{*}{ Vegetable } & \multirow{2}{*}{ Metal } & \multicolumn{5}{|c|}{ Coefficients of the interpolation polynomials } & \multirow{2}{*}{ Error, \% } \\
\hline & & $c_{0}$ & $c_{1}$ & $c_{2}$ & $c_{3}$ & $c_{4}$ & \\
\hline \multirow{12}{*}{ Cucumbers } & \multirow{4}{*}{$\mathbf{C u}$} & 5.647 & $6.269 \cdot 10^{-3}$ & 0 & 0 & 0 & 19.454 \\
\hline & & 5.284 & 0.011 & $-7.583 \cdot 10^{-6}$ & 0 & 0 & 17.047 \\
\hline & & 4.498 & 0.034 & $-9.401 \cdot 10^{-5}$ & $8.232 \cdot 10^{-8}$ & 0 & 3.285 \\
\hline & & 4.847 & 0.02 & $3.612 \cdot 10^{-6}$ & $-1.131 \cdot 10^{-7}$ & $1.34 \cdot 10^{-10}$ & $1.053 \cdot 10^{-13}$ \\
\hline & \multirow{4}{*}{$\mathbf{P b}$} & 7.789 & 0.018 & 0 & 0 & 0 & 74.402 \\
\hline & & 4.457 & 0.1 & $-2.635 \cdot 10^{-4}$ & 0 & 0 & 58.818 \\
\hline & & 0.164 & 0.426 & $-4.1 \cdot 10^{-3}$ & $9.641 \cdot 10^{-6}$ & 0 & 9.272 \\
\hline & & -0.86 & 0.584 & $8.039 \cdot 10^{-3}$ & $4.016 \cdot 10^{-5}$ & $-6.526 \cdot 10^{-8}$ & $5.97 \cdot 10^{-13}$ \\
\hline & \multirow{4}{*}{$\mathbf{Z n}$} & 30.884 & 0.066 & 0 & 0 & 0 & 14.042 \\
\hline & & 33.759 & 0.045 & $1.911 \cdot 10^{-5}$ & 0 & 0 & 12.642 \\
\hline & & 28.007 & 0.13 & $-1.935 \cdot 10^{-4}$ & $1.319 \cdot 10^{-7}$ & 0 & 7.389 \\
\hline & & 32.489 & 0.032 & $2.342 \cdot 10^{-4}$ & $-4.875 \cdot 10^{-7}$ & $2.845 \cdot 10^{-10}$ & $4.609 \cdot 10^{-13}$ \\
\hline
\end{tabular}

The polynomial interpolations of the heavy metal content in the plant at harvest depending on the heavy metal content in the soil are graphically represented in Figure 1.

a)

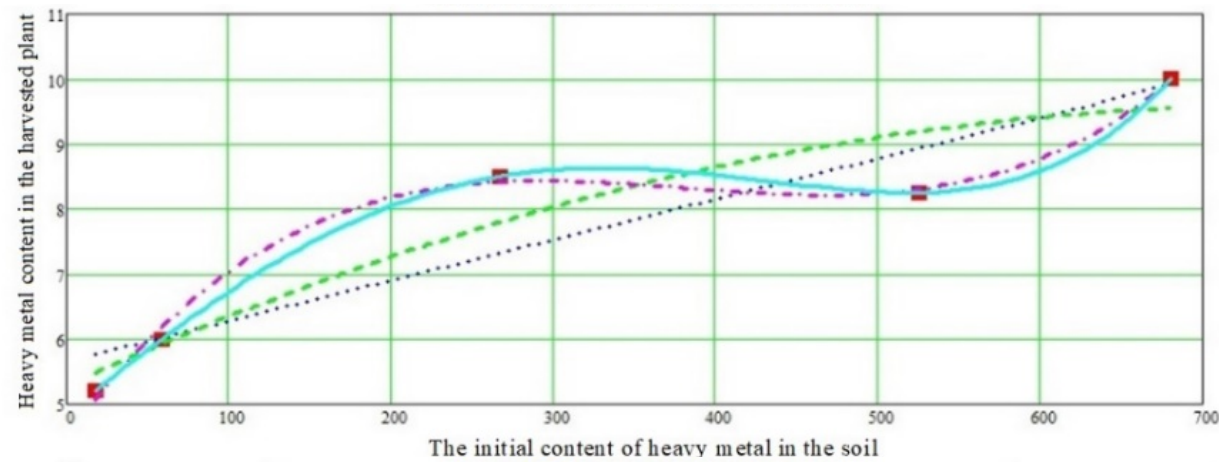

b)

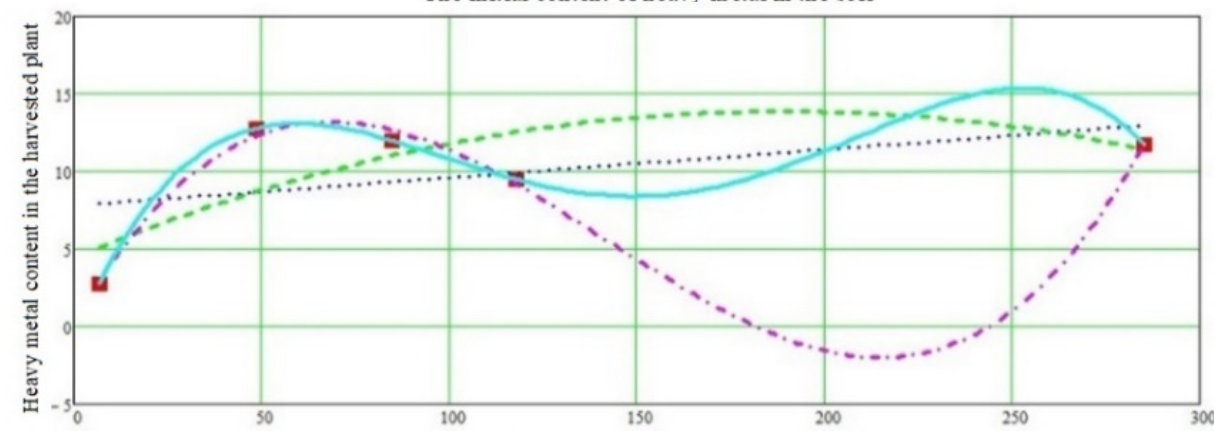

c)

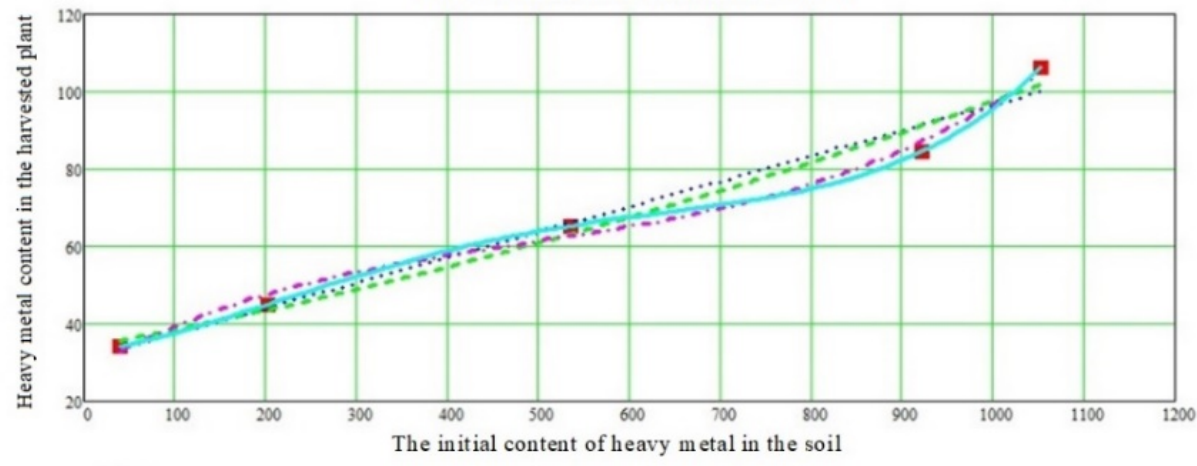

Experimental data .... First degree polynomial interpolation . - Second degree polynomial interpolation

-. Third degree polynomial interpolation _ Fourth degree polvnomial interpolation

Fig. 1. Graphical representations of the interpolations of heavy metal content in the plant (cucumbers) at harvest according to the heavy metal content in the soil: $\mathrm{a}-\mathrm{Cu} ; \mathrm{b}-\mathrm{Pb} ; \mathrm{c}-\mathrm{Zn}$ 
Next, the interpolations of first, second, third and fourth degree and the hyperbolic interpolation curve of the translocation coefficient are given, depending on the concentration of heavy metal in the soil.

$$
C_{t}\left(C_{i s}\right)=c_{0}+c_{1} C_{i s}+c_{2} C_{i s}^{2}+c_{3} C_{i s}^{3}+c_{4} C_{i s}^{4} \text {. }
$$

For the translocation coefficient, the way, in which the experimental data are placed, shows a possible monotonous descent, possibly asymptotic, mathematically modelable according to the formula:

$$
C_{t}\left(C_{i s}\right)=\frac{c_{0}}{C_{i s}}+c_{1} .
$$

The coefficients of the polynomials (3) and those of the hyperbola (4) are shown in Table 4, and respectively in Table 5.

Table 4

\section{Interpolation equations corresponding to the translocation}

\begin{tabular}{|c|c|c|c|c|c|c|c|}
\hline \multirow{2}{*}{ Vegetable } & \multirow{2}{*}{ Metal } & \multicolumn{5}{|c|}{ Coefficients of the interpolation polynomials } & \multirow{2}{*}{ Error, \% } \\
\hline & & $c_{0}$ & $c_{1}$ & $c_{2}$ & $c_{3}$ & $c_{4}$ & \\
\hline \multirow{12}{*}{ Cucumbers } & \multirow{4}{*}{$\mathrm{Cu}$} & 0.19 & $-3.136 \cdot 10^{-4}$ & 0 & 0 & 0 & 169.64 \\
\hline & & 0.245 & $-1.094 \cdot 10^{-3}$ & $1.148 \cdot 10^{-6}$ & 0 & 0 & 123.307 \\
\hline & & 0.286 & $-2.288 \cdot 10^{-3}$ & $5.738 \cdot 10^{-6}$ & $-4.372 \cdot 10^{-19}$ & 0 & 99.395 \\
\hline & & 0.415 & $-7.355 \cdot 10^{-3}$ & $3.904 \cdot 10^{-5}$ & $-7.634 \cdot 10^{-8}$ & $4.936 \cdot 10^{-11}$ & $4.653 \cdot 10^{-12}$ \\
\hline & \multirow{4}{*}{$\mathrm{Pb}$} & 0.31 & $-1.142 \cdot 10^{-3}$ & 0 & 0 & 0 & 89.319 \\
\hline & & 0.435 & $-4.183 \cdot 10^{-3}$ & $9.829 \cdot 10^{-6}$ & 0 & 0 & 6.995 \\
\hline & & 0.433 & $-4.033 \cdot 10^{-3}$ & $8.062 \cdot 10^{-6}$ & $4.44 \cdot 10^{-9}$ & 0 & 6.853 \\
\hline & & 0.418 & $-1.798 \cdot 10^{-3}$ & $-4.75 \cdot 10^{-5}$ & $4.349 \cdot 10^{-7}$ & $-9.206 \cdot 10^{-10}$ & $7.649 \cdot 10^{-13}$ \\
\hline & \multirow{4}{*}{$\mathrm{Zn}$} & 0.587 & $-5.594 \cdot 10^{-4}$ & 0 & 0 & 0 & 155.184 \\
\hline & & 0.831 & $-2.355 \cdot 10^{-3}$ & $1.626 \cdot 10^{-6}$ & 0 & 0 & 91.914 \\
\hline & & 1.013 & $-5.077 \cdot 10^{-3}$ & $8.362 \cdot 10^{-6}$ & $-4.179 \cdot 10^{-9}$ & 0 & 48.423 \\
\hline & & 1.136 & $-7.765 \cdot 10^{-3}$ & $2.002 \cdot 10^{-5}$ & $-2.107 \cdot 10^{-8}$ & $7.757 \cdot 10^{-12}$ & $1.062 \cdot 10^{-12}$ \\
\hline
\end{tabular}
coefficient in cucumbers (fruit)

\section{Hyperbolic interpolation equations corresponding} to the translocation coefficient

Table 5

\begin{tabular}{|c|c|c|c|}
\hline \multirow{2}{*}{ Vegetable } & \multirow{2}{*}{ Metal } & \multicolumn{2}{|c|}{ Hyperbola coefficients } \\
\cline { 3 - 4 } & & $\boldsymbol{c}_{\mathbf{0}}$ & $\boldsymbol{c}_{\mathbf{1}}$ \\
\hline \multirow{3}{*}{ Cucumbers } & $\mathrm{Cu}$ & 5.075 & 0.01 \\
\cline { 2 - 4 } & $\mathrm{Pb}$ & 2.102 & 0.105 \\
\cline { 2 - 4 } & $\mathrm{Zn}$ & 31.551 & 0.064 \\
\hline
\end{tabular}

The polynomial interpolations for the translocation coefficient are graphically represented in Fig. 2.

Considering all the cases of cucumbers grown in soil contaminated with different concentrations of heavy metal, it is observed that in 3 cases, respectively for $\mathrm{Cu}, \mathrm{Pb}$ and $\mathrm{Zn}$, there is a tendency of increased amount of heavy metal accumulated in the plant with the increase of the initial concentration of heavy metal in the soil.

The analyzes confirmed the presence in cucumbers of the three metals, the highest content was zinc, both in the case of metals applied separately in the soil with values between 45.0$106.3 \mathrm{mg} \cdot \mathrm{kg}^{-1}$ compared to $34.1 \mathrm{mg} \cdot \mathrm{kg}^{-1}$ in the case of uncontaminated soil, and in the case of metals applied in a mixture in the soil with values between $45-54.8 \mathrm{mg} \cdot \mathrm{kg}^{-1}$. The content of cucumber metals decreases in the following order: $\mathrm{Zn}>\mathrm{Cu}>\mathrm{Pb}$ in the case of metals applied mixed in the soil and $\mathrm{Zn}>\mathrm{Pb}>\mathrm{Cu}$ in the case of metals applied separately in the soil.

Considering all the cases of cucumbers cultivated with different concentrations of heavy metals in the soil, a decreasing tendency of the translocation coefficient of the heavy metal from the soil to the 
plant is observed, with the increase of the initial concentration of the heavy metal in the soil.As a general conclusion, it would result that for cucumbers the bioaccumulation of heavy metal is weaker with higher initial concentration of heavy metal in the soil. This means that the more intensely the soil will be infested with heavy metals, the more difficult it will be to measure the soil with this plant.

a)

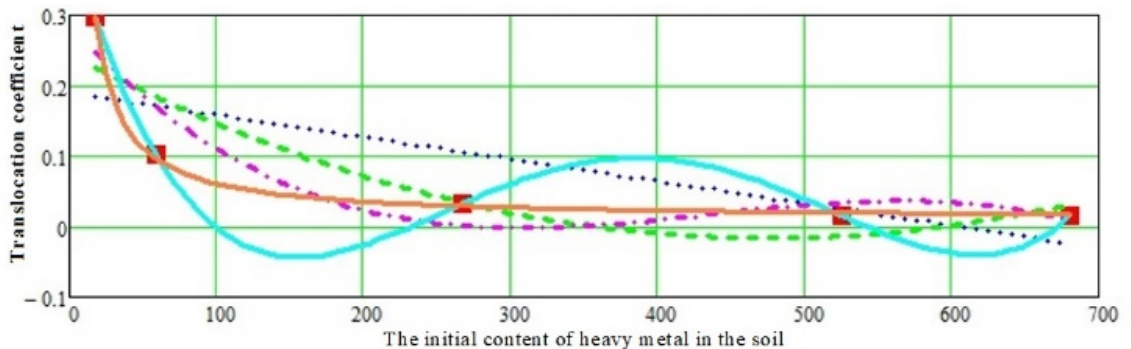

b)

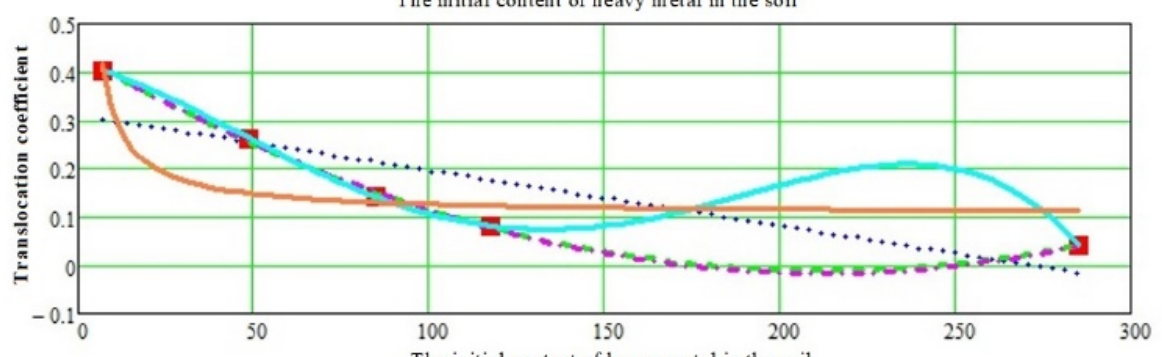

c)

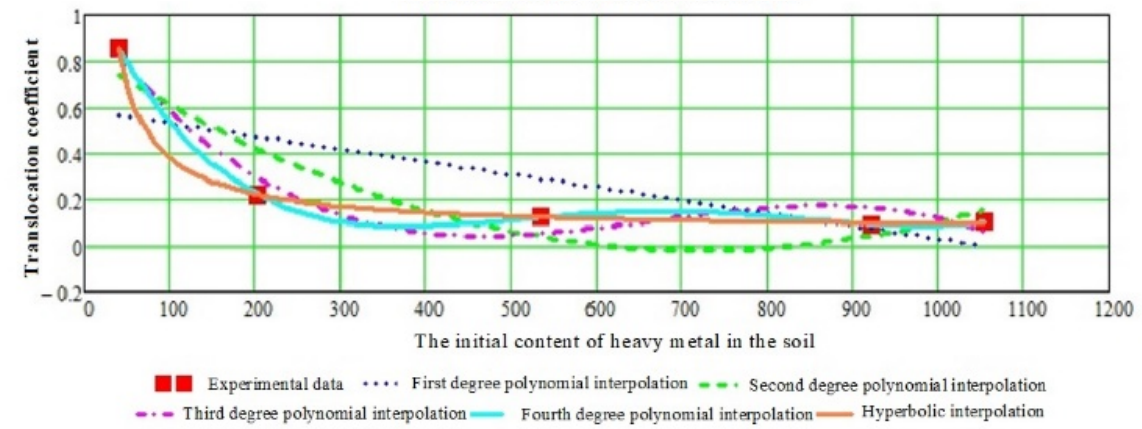

Fig. 2. Graphical representations of the interpolations

for the translocation coefficient in cucumbers: $\mathrm{a}-\mathrm{Cu} ; \mathrm{b}-\mathrm{Pb} ; \mathrm{c}-\mathrm{Zn}$

\section{Conclusions}

1. Interpolation polynomials of first, second degree are the most usable, because they have small variations between experimental points. The third, fourth degree polynomial curves show large relative variations between the experimental points, and therefore their use presents the risk of producing large errors, although, for example, restricting only to the set of experimental points, the fourth-degree polynomial passes exactly through the experimental points.

2. In general, the interpolation curves show the increasing tendency of the final concentration of heavy metal in the plant (at the final stage of vegetation/harvesting) and the decrease in the translocation coefficient of heavy metal in the plant at the end of the experiments. For the translocation coefficient, a pronounced tendency of hyperbolic decrease of this coefficient was noticed with the initial concentration of heavy metal in the soil. For this reason, it was considered as hyperbolic interpolation formula (relation 3), which proves adequate with some exceptions in which the experimental data do not notice the above-mentioned tendency.

3. Statistical mathematical models provided by formulas (2), (3) and (4), which generic coefficients, for each particular case, are given in Tables 3, 4 and 5, can be used for interpolation, the calculation of any heavy metal concentration in the plant or translocation coefficient, only in the experimental range considered for the initial concentration of heavy metal in the soil.It is observed that there are negative and relatively significant correlations, this allows the conclusion that the plants extract zinc with priority, therefore, the plant has its own filter for heavy metals and extracts more heavy metals preferentially. 
4. Polynomial representations are a primary and usual form of statistical models with practical applications in both scientific research and agricultural management. Using such formulas, it is possible to calculate the necessary plants for phytoremediation, or to classify the production within the limits stipulated by the health standards; phytoremediation processes can be optimized or the optimal identification of crop plots can be considered, considering the use for commercialization/consumption or for phytoremediation processes.

5. The results obtainedshow that such experiences and statistical modeling can be the fundaments for building dynamic mathmatical models that can simulate the life of a plant, even that of several generations of plants, and highlight the possible mechanisms of self-defense developed by plants, adaptations to the new environmental conditions/variables (climate change), possibilities of recovery in time of the qualities of some plants.

\section{Acknowledgements}

This work was supported by a grant of the Romanian Research and Innovation Ministry, through Programme 1 - Development of the national research-development system, subprogramme 1.2 Institutional performance - Projects for financing excellence in RDI, contract no. 16PFE and bya grant of the Ministry of Agriculture and Rural Development, contract of sector financing, ADER type,no. 25.4.1 "Technology for obtaining biofertilizers and/or bioinsecticides, for ecological production systems".

\section{References}

[1] Kamran S., Shafaqat A., Hameed S., Afzal S.,Samar F., Muhammad B. S.,Bharwana A. S., Hafiz M. T. Heavy metal contamination and what are the impacts on living organisms, Greener Journal of Environmental Management and Public Safety, vol. 2 (4), 2013, pp. 172-179.

[2] Sandeep G., Vijayalatha K.R., Anitha T. Heavy metal and its impact in vegetable crops, International Journal of Chemical Studies; vol. 7(1), 2019, pp. 1612-1621.

[3] Zafarzadeh A., Rahimzadeh H., Mahvi A. H. Health Risk Assessment of Heavy Metals in Vegetables in an endemic esophageal cancer region in Iran, Health Scope, 7(3):e12340, 2018, doi: 10.5812/jhealthscope. 12340 .

[4] Zhao X.G., Li B., Gao M., Li Y.Detection and analysis of heavy metals in vegetables in Xinzhu vegetable base, Advances in Engineering Research, vol. 94, $2^{\text {nd }}$ International Conference on Sustainable Development (ICSD 2016), pp. 252-254.

[5] AbouAuda M., Abu Zinada I., El Shakh Ali E. Accumulation of heavy metals in crop plants from Gaza Strip, Palestine and study of the physiological parameters of spinach plants, Journal of the Association of Arab Universities for Basic and Applied Sciences, vol. 10, 2011, pp. 21-27.

[6] Ekpe I.I., Okere, S. E., Agim L.C, Ahukaemere C.M, Ihemtuge S. C., Okoye C., Onuora M.D., Nwaigwe M.O.Effect of Organic Wastes on Soil Heavy Metal Concentration and Growth Characteristics of Cucumber (Cucumis sativus L.) in an Ultisol, FUTOJNLS, Vol. 2, Issue 2, 2016, pp. 335-345.

[7] Igwegbe A. O., Agukwe C. H., Negbenebor C. A., A survey of heavy metal (lead, cadmium and copper) contents of selected fruit and vegetable crops from Borno State of Nigeria, International Journal of Engineering and Science, Vol. 2, Issue 1, 2013, pp. 1-5.

[8] Lacatusu R., Lacatusu A.R., Vegetable and fruits quality within heavy metals polluted areas in Romania, Carpth. J. of Earth and Environmental Sciences, Vol. 3, No. 2, 2008, pp. 115-129.

[9] Harmanescu M., Alda L.M., Bordean D.M., Gogoasa I., Gergen I., Heavy metals health risk assessment for population via consumption of vegetables grown in old mining area; a case study: Banat County, Romania, Chemistry Central Journal, vol. 5:64, 2011, [online][11.02.2020] Available at: http://journal.chemistrycentral.com/content/5/1/64.

[10] Gergen, I., Analysis of agri-food products,Eurostampa Publishing House, Timişoara, 2004.

[11]Gergen, I.,Analytical chemistry and physico-chemical analysis,Mirton Publishing House, Timişoara 1998.

[12] Gergen, I., Chemical and physico-chemical methods for controlling the quality of plant food products, University Horizons Publishing House, Timişoara, 2003. 
[13] Methodology for agrochemical analysis of soils to determine the need for amendments and fertilizers. I.C.P.A., Bucharest, 1983.

[14] SR ISO 11047:1998, Soil quality. Determination of Cd, Cr, Co, Cu, Mn, Ni, and Zn. Methods by flame atomic absorption spectrometry and electrothermal vaporization.

[15] Cardei P., Tudora C., Theoretical Research on evolution of health of plants afected by heavy metal absorbtion process. 17th International Conference Engineering for rural development Jelgava: Latvia University of Life SCiences and Technologies, Faculty of Engineering, 2018, pp. 893-897.

[16] Păunescu I., David L., Experimental research bases of biotechnical systems, Printech Publishing, Bucharest, 1999.

[17] Mathcad 2001 Professional - User`s guide with reference manual, United States of America [online][11.02.2020] Available at: www.mathsoft.com 